\title{
Specific schistosomiasis treatment as a strategy for disease control
}

\author{
José Rodrigues Coura ${ }^{1}{ }^{+}$, Maria José Conceição ${ }^{2}$ \\ 'Laboratório de Doenças Parasitárias, Instituto Oswaldo Cruz-Fiocruz, Av. Brasil 4365, 21040-360 Rio de Janeiro, RJ, Brasil \\ ${ }^{2}$ Serviço de Doenças Infecciosas, Hospital Universitário Clementino Fraga Filho, Faculdade de Medicina, \\ Universidade Federal do Rio de Janeiro, Rio de Janeiro, RJ, Brasil
}

\begin{abstract}
The great hope for schistosomiasis treatment began with the development of oxamniquine and praziquantel. These drugs can be administered orally in a single dose and have a high curative power with minor side effects. In this study, we carried out a field experiment involving a population of 3,782 people. The population was examined at four localities in Minas Gerais within the valleys of the Doce and Jequitinhonha Rivers. In this cohort, there were 1,790 patients infected with Schistosoma mansoni (47.3\%) and we showed that only 1,403 (78.4\%) could be treated with oxamniquine in a single dose of 12.5-20 $\mathrm{mg} / \mathrm{kg}$ orally. The other 387 (21.6\%) were not treated during the first stage because of contraindications (pregnancy or impeditive diseases), absences or refusals. It was observed that, on average, $8.8-17 \%$ of the infected patients continued to excrete $\mathrm{S}$. mansoni eggs at the end of the 2nd month after treatment and 30-32\% of the cohort was infected by the end of the 24th month. In one of the areas that we followedup for a total of 30 years, the prevalence of the infection with S. mansoni fell from 60.8-19.3\% and the hepatosplenic form of the disease dropped from 5.8-1.3\%. We conclude that specific treatment of schistosomiasis reduces the prevalence of infection in the short-term and the morbidity due to schistosomiasis in medium to long-term time frames, but does not help to control disease transmission.
\end{abstract}

Key words: schistosomiasis - specific treatment - transmission - morbidity control

The first efficient treatments for schistosomiasis were carried out using trivalent antimonials. The use of tartar emetic was initiated as a treatment for this disease by McDonagh, in 1915. Christopherson then consolidated it in 1918 and gave the first description and published the details of the positive results obtained in relation to schistosomiasis cure with this drug when administered intravenously.

In 1912, Gaspar Vianna was the first to use tartar emetic in Brazil, which was administered for the treatment of mucocutaneous leishmaniasis. From 1920 onwards, it started to be used for schistosomiasis treatment, initially by Jesuíno Maciel (1920), and professionally on a large scale by Heraldo Maciel $(1924,1925)$ in the Health Service of the Brazilian Navy.

New antimonial compounds other than tartar emetic (i.e., the double salt, potassium antimony tartrate) started to appear in later years. Among these were homologues of tartar emetic including: sodium antimony tartrate (double salt), neoantimosan, Fuadin ${ }^{\circledR}$, Reprodal ${ }^{\circledR}$ or Stibophen ${ }^{\circledR}$ (sodium antimony disulfate), Anthiomaline ${ }^{\circledR}$ (sodium antimony thiomalate), Tiostan ${ }^{\circledR}$ (sodium antimony gluconate) and Astiban $^{\circledR}$ (sodium antimony dimercaptan). In addition to intravenous administration, the last five compounds on this list could also be applied intramuscularly. However, all of these compounds were extremely toxic for the cardiac muscle and painful when applied intramus-

\footnotetext{
+ Corresponding author: coura@ioc.fiocruz.br

Received 28 January 2009

Accepted 5 August 2009
}

cularly. Many deaths due to muscle fibre fragmentation (fragmentatio cordis) were observed (Dias 1949). In an electrocardiographic study on 120 patients treated with Astiban $^{\circledR}$ and 30 treated with Fuadin ${ }^{\circledR}$, Coura et al. (1963) observed significant "ischemic" abnormalities, which they correlated with the dose and frequency of application (1, 2 or 3 times a week, or daily), showing the cumulative effect of the drug. In addition, they also demonstrated both clinically and experimentally that the "ischemia" was due to arteriolar paralysis of the musculature with dilatation and delay in circulation (examination of the eye fundus in patients and histopathology of the hearts of guinea pigs treated with the drugs).

Despite the limitations resulting from the toxic effects of trivalent antimonials, large-scale pioneering studies were carried out in Brazil with selective treatment. Among these are the studies by Heraldo Maciel (1924, 1925, 1929), Get Jansen (1946), Hoel Sette (1953) and Rodrigues da Silva (1958), which made important contributions towards knowledge of the results and difficulties of chemotherapy as a potential control method for schistosomiasis.

Since then, specific treatment for Manson's schistosomiasis has been one of the critical measures for controlling the morbidity of this disease in distant areas. There are difficulties in using such a treatment as a mass treatment for the entire population, because of side effects, temporary absences and refusals among individuals. Another key factor in the limitation of treatment is the importance that re-infection plays. Nonetheless, it has clearly been demonstrated that use of specific treatment may reduce the progression of the disease to severe forms and these results were confirmed by Kloetzel (1963).

Specific treatment for schistosomiasis has emerged over the last 30 years, in part due to the launch of oxam- 
niquine and praziquantel. Treatment with these drugs is an important tool for medium to long-term morbidity control and an important tool for short-term prevalence control.

Oral chemotherapy - The great hope for schistosomiasis treatment began with the development of the oral medication aminonitrothiazole, also known as niridazole or Ambilhar ${ }^{\circledR}$. However, expectations were thwarted, because of the low cure rates, the need for several doses (5-7 days) and severe side effects consisting of neuropsychological phenomena (convulsions and hallucinations), digestive manifestations and possible teratogenic effects (Katz et al. 1977). Thioxanthone and its derivatives, Miracil D and hycanthone, became the new hope. Bayer discovered Miracil D (lucanthone) in Germany during World War II. Following the war, in the late 1940s and 1950 s, it was incorporated in the American company Schering-Winthrop. Miracil D was considered to be the first effective oral schistosomicide, but was soon abandoned due to its side effects. The critical side effects that hampered widespread use of Miracil D were cardiovascular, neuropsychological and digestive in their nature. Rodrigues da Silva (1955) conducted an extensive review on this and other oral drugs for schistosomiasis treatment in his full professorship thesis for the School of Medical Sciences of Rio de Janeiro, which today is part of the State University of Rio de Janeiro.

During the 1960s, studies on hydroxymethylation, also known as lucanthone or Miracil D, gave rise to a potent drug with the possibility of providing a disease cure in a single intramuscular or oral dose. This drug was named hycanthone and had the capacity to cure more than $90 \%$ of cases treated. However, it was soon observed that, in certain cases, the drug had the potential to cause acute liver necrosis (Andrade et al. 1974), thus causing death due to liver failure. These complications then led to immediate abandoning of the drug.

Finally, in the 1970s, Pfizer, in England, produced oxamniquine and Merck, in Germany, produced praziquantel. These drugs were shown to have a high curative power against schistosomiasis when used orally in a single dose, or as a series of two doses. Additionally, they showed few side effects. Thus, they conformed to the standards for ideal drugs proposed by the World Health Organisation. These drugs have been extremely important for treating individuals with schistosomiasis, both for short-term prevalence control and for medium to long-term morbidity control.

Oxamniquine - Oxamniquine originated from lucanthone (Miracil D), which after hydroxymethylation gave rise to hycanthone (UK 3883), or Etrenol ${ }^{\mathbb{}}$, which was abandoned because of its hepatotoxic action. Oxidation of UK 3883 by the fungus Aspergillus sclerotiorum, developed by Pfizer in England, gave rise to UK 4271. This drug was subsequently named oxamniquine by Foster $(1973,1987)$ and the commercial equivalent in Brazil is Mansil ${ }^{\mathbb{B}}$. This was distributed as $250 \mathrm{mg}$ capsules or in suspensions of $250 \mathrm{mg}$ per $5 \mathrm{~mL}$. The mechanism of action for oxamniquine was characterised by an early inhibition of oviposition by the females and by the presence of tegumental lesions on worms moving to the liver, where they were then phagocytised.
The first drug trials performed against schistosomiasis in Brazil, during the 1970s to 1980s, revealed high cure rates and an almost complete absence of side effects from the use of this drug. Initially, oxamniquine was administered intramuscularly in a single dose of 7.5 $\mathrm{mg} / \mathrm{kg}$ and later it was given orally in a dose of 12.5-15 $\mathrm{mg} / \mathrm{kg}$ for adults and $15-20 \mathrm{mg} / \mathrm{kg}$ for children (Coura et al. 1973, 1980, 1992, Katz et al. 1973, 1976, 1980, Prata 1976, Bina \& Prata 1980, Prata et al. 1980). Some of the side effects most frequently reported were dizziness, nausea, headaches and sleepiness. Less frequently, vomiting and abdominal pains were also reported (Katz 2008). On rare occasions, excitability, hallucinations and localised convulsions were observed.

Praziquantel - Praziquantel was initially developed by Merck and then further developed together with Bayer, in Germany. This drug is a derivative of the pyrazinoisoquinoline chemical group, which was discovered while researching new tranquilisers. Soon afterwards, praziquantel was synthesised by the Chinese and South Korean pharmaceutical industry. Today, it is also produced by Farmanguinhos, which belongs to the Fiocruz in Brazil (Katz 2008). It is a rapidly absorbed drug that is used orally and is metabolised in the liver, attaining high blood concentrations. Thus, it reaches many tissues beyond the digestive system, which explains its broad spectrum of action as a schistosomicide and cestocide. The drug has a significant action against taeniasis, cysticercosis and different species of Schistosoma including: hematobium, mansoni, japonicum, mecongi and intercalatum, as shown in preliminary studies by Davis and Wegner (1979), Ishisaki et al. (1979) and Katz et al. (1979), among others. It has been commercialised in Brazil by Merck under the names Cestox ${ }^{\circledR}$ and Cisticid $^{\circledR}$ and under the generic name Praziquantel ${ }^{\mathbb{Q}}$. The drug is distributed in tablets ranging from 150-500 mg. It acts by paralysing the worms and increasing their cell membrane permeability, thus making it possible for the worms to be phagocytised by immune cells. This drug is used at a daily dose of $40-60 \mathrm{mg} / \mathrm{kg}$, divided into two doses, thereby obtaining a parasitological cure rate of $80-90 \%$. In acute and neurological cases of schistosomiasis, its use must be preceded by $1 \mathrm{mg} / \mathrm{kg}$ of prednisone, 24-48 $\mathrm{h}$ before the specific treatment. The levels of this corticoid need to be progressively reduced over a 7-10day period in cases of the acute form and maintained for 2-3 months in cases of the neurological form. The main side effects from praziquantel are anorexia, abdominal pains, diarrhoea, nausea, vomiting, headaches, tiredness, dizziness, skin eruptions and occasional feelings of forgetfulness. The side effects from both oxamniquine and praziquantel are temporary and they typically recede within 24-48 $\mathrm{h}$ after administration.

Perspectives for schistosomiasis control: importance of individual and mass treatment strategies - Classically, the attempts to control schistosomiasis have been based on using one or more of the following methods, separately or in association with each other: (i) control over the intermediate host by means of molluscicides, biological combat or competition of any nature, (ii) ba- 
sic sanitation and water supply with different degrees of improvement and complexity according to the resources available, location and human population groups that will be affected, (iii) sanitary education, going from very basic information without any defined targets to processes for preparing communities to participate at different levels of integration within the process, (iv) protection for individuals and professional groups with regard to personal contact with water infested by intermediate host snails, the use of clothing that is impermeable to cercaria penetration or even the experimental use of substances with potential for blocking such penetration and, finally, (v) treatment for infected populations with different drugs, going from trivalent antimonials to the most recent single-dose oral products such as oxamniquine and praziquantel.

None of the aforementioned methods can be considered to be extensively capable of separately providing schistosomiasis control, except in very restricted areas and population groups. Such is also the case with molluscicides; when these are applied with a very rigorous technique and great regularity, they need to be accompanied by a strict surveillance program over very long periods, or almost indefinitely, making such programs very expensive and practically less feasible in countries of large territorial extent and disseminated planorbid fauna, such as Brazil. In addition, there are problems related to pollution and negative consequences for agriculture and some types of fauna. On the other hand, experiments regarding biological control have not produced convincing arguments regarding their efficiency when used at larger scales.

Improvements in basic sanitation and treated water supplies would clearly be an important solution for disease control problems. This is not only true in the case of schistosomiasis in heavily populated areas, but also in relation to other waterborne diseases. However, there would still be difficulties in controlling such diseases among dispersed rural populations and especially among groups of workers who are obliged to come into contact with water, such as farm labourers, since it would be impossible to have complete sanitation of the inhabited world.

Sanitary education as an isolated measure would certainly not be reasonable in a program for schistosomiasis control. However, active participation by the community in the various stages of comprehension and application of control measures would, in our opinion, be the only way to achieve enduring results, with a high-quality yield in terms of controlling not only schistosomiasis, but also many other diseases. In reality, the experience obtained thus far in this field in Brazil has been extremely fragmentary and fragile. This is partly because of timidity or interference with a political connotation and due to the limitations and fragility of the programs themselves and partly from the point of view of either content or a lack of support and credit from sponsoring organisations.

Protection of individuals and professional groups against the risk of cercarial penetration through the skin has great limitations not only the number of people to be protected, but also for the technical and operational difficulties often seen. It is almost impossible to use boots, gloves and other impermeable clothing under the cultur- al and working conditions that rural populations have to operate within, particularly those having continual contact with water. Alternatively, protection to avoid contact between humans and water infected with Schistosoma cercarias requires a series of basic measures, such as the construction of washhouses, rectification, cleaning or covering of ditches and streams and sanitary education measures. This development is necessary, despite the limitations and difficulties that are already known and prior results that appear to not have been properly evaluated in our country. Certainly, the only safe measure for individual and collective protection would be to increase people's resistance and immunity to infections. This would be possible if an effective vaccine were available, which does not seem viable in the foreseeable future.

The concept of mass treatment is strictly the same as simultaneous treatment of the entire population of a community, which would indiscriminately include both sick and healthy individuals, with and without infection of all ages and both genders. From an ethical point of view, it would be impossible to apply this concept unless the drugs were absolutely nontoxic and freely available. This is almost never the case, even with "mass vaccination", in which some cases with absolute contraindications are observed. From a practical point of view a mass treatment is the simultaneous or "almost simultaneous" treatment of a "large number" of people who are representative of a community, as defined by Martins, according to Prata (1976).

In the particular case of schistosomiasis, it appears to us to be more appropriate to apply the concept of selective treatment on a large scale. This process would consist of the following selection elements: (i) individuals with active infection, (ii) individuals without any absolute contraindications and (iii) individuals who allow treatment to be administered without any proof that they are infected. These three conditions, together with an approximate false-negative rate of $10-15 \%$ from faecal examinations, greatly limit the use of specific treatment as a schistosomiasis control measure. This last difficulty (false-negative cases) could be surmounted by excluding the first selection criterion and thus treating all individuals in the community, regardless of whether or not they are infected, provided that they do not present absolute contraindications to the treatment and do not oppose treatment. This would leave us closer to the concept of mass treatment but would enormously increase the operational costs due to the quantity of medication that would be used unnecessarily, i.e., regardless of the prevalence of the infection in the community, although though this cost would be minimised by dispensing with laboratory diagnosis of infection. On the other hand, the risk of toxic and side effects would be increased because of the extent of the treatment.

The first studies on large-scale selective treatment for schistosomiasis in Brazil, such as those conducted by Heraldo Maciel (1929), Get Jansen (1946), Hoel Sette (1953) and Rodrigues da Silva (1958) using trivalent antimonials, made important contributions towards our knowledge of the results and difficulties of chemotherapy as a control measure for schistosomiasis. Since then, 
it can be said that specific treatment for Manson's schistosomiasis has become an important measure for controlling the disease among populations that are distant from urban centres. The difficulties in this treatment are largely due to side effects, the impossibility of treating the entire infected population and re-infections in endemic areas. This greatly limits the use of this control measure in these rural areas. Nonetheless, it has clearly been demonstrated that its use can reduce the progression of the disease to severe forms, as was confirmed subsequently by Kloetzel (1963).

With the discovery of drugs for single-dose application such as hycanthone and other drugs with lower toxicity, such as oxamniquine and praziquantel, it has become possible to undertake larger-scale campaigns, such as the one developed by the Ministry of Health $(1975,1979)$, in the Northeaster Region of Brazil (Machado 1982). Unfortunately, the results from these campaigns could not be properly investigated, although such evaluations would have been extremely important for disease control efforts. In experimental field studies conducted on a smaller scale, Bina and Prata (1970, $1974)$ in Bahia, Katz et al. $(1977,1980)$ in Minas Gerais (MG) and Coura et al. (1980, 1984, 1992), Conceição and Borges-Pereira (2002) and Conceição et al. (2007) in other areas of MG have demonstrated the possibility of reducing the rates and intensities of infection among treated individuals who remained in the endemic area. Furthermore, they have shown a reduction in the progression of the disease to severe forms. These authors attributed their findings to an increased resistance to re-infection among the treated individuals. However, Katz et al. (1978) did not obtain similar results regarding re-infections of previously treated patients in $\mathrm{MG}$ and observed practically the same rates of infection at a time of seven years after treatment.

Personal experience with specific treatment for schistosomiasis as a strategy for control - It has already been proven that large-scale specific treatment for schistosomiasis in endemic areas (excluding the cases with contraindications) can reduce the prevalence of infection over the short term, as well as the morbidity due to the disease over the medium and long term (Jansen 1946, Sette 1953, Rodrigues da Silva 1958, Kloetzel 1963, 1972, Bina \& Prata 1974, 1980, Prata 1976, Katz et al. 1977, 1980, Coura et al. 1980, 1992, Prata et al. 1980, Machado 1982, Conceição et al. 2002, 2007). This advance can then be consolidated through repeated treatments (Coura 1995, Coura \& Amaral 2004).

A field experiment was carried out by Coura et al. (1980), starting in 1974, and involving a population of 3,782 people examined at four localities in $\mathrm{MG}$, in the valleys of the Doce and Jequitinhonha Rivers. Of these 3,782 people, 1,790 were infected with $S$. mansoni (47.3\%); however, only $1,403(78.4 \%)$ could be treated with oxamniquine in a single dose of $12.5-20 \mathrm{mg} / \mathrm{kg}$ orally. The remaining $387(21.6 \%)$ were not treated during the first stage, because of contraindications (pregnancy or impeditive diseases), absences or refusals to participate. Through following up the treated patients with faecal examinations using the Kato-Katz method in the 2nd, 4th, 8th, 12th, 18th and 24th months after the treatment, it was observed that, on average, $8.8-17 \%$ (Figs 1,2) of those treated were continuing to eliminate $S$. mansoni eggs at the end of the 2nd month after treatment (therapeutic failure). Further, re-infection among the "cured" individuals had occurred, on average, among $4-6 \%$ by the end of the 4 th month after treatment, among $10-13.5 \%$ by the end of the 8 th month, among $15 \%$ by the end of the 12th month, among $20 \%$ by the end of the 18th month and among $30-32 \%$ by the end of the 24th month period, considering that the initial prevalence of infection with $S$. mansoni before the treatment ranged from 42 $60.8 \%$ between the four study areas. The re-infection rate was proportional to the prevalence of the initial infection in each of the areas and the parasite load went down from 216 eggs per gram of faeces before the treatment to levels of 86.6 in one of the areas, which was taken as a model (São Geraldo do Baixio, Galiléia, Doce River valley). Unfortunately, then went up again to 159.8 eggs per gram of faeces 24 months after the treatment (Fig. 3).

In one of the areas that was followed for up to 30 years (Conceição et al. 2007), the prevalence of infection with $S$. mansoni fell from $60.8 \%$ in 1973 to $19.3 \%$ in 2003. This occurred after many treatments, thus showing that the treatment alone without any other control measures reduced the prevalence, but was not sufficient

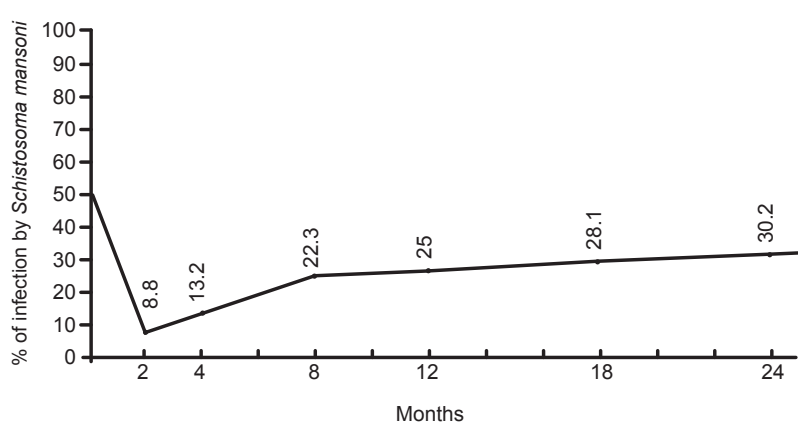

Fig. 1: therapeutic failure $(8.8 \%)$ and reinfection rate from $2-24$ months of patients treated with oxaminiquine in São Geraldo do Baixio, Galiléia, Minas Gerais.

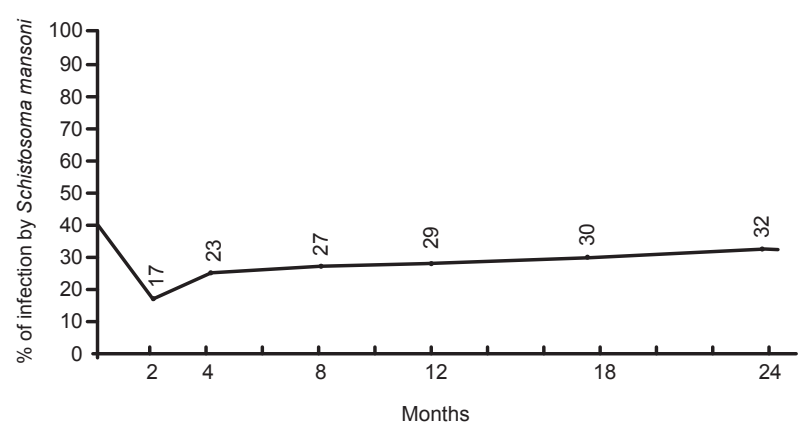

Fig. 2: therapeutic failure (17\%) and reinfection rate from 2-24 months of patients treated with oxaminiquine in Itanhomi, Minas Gerais. 


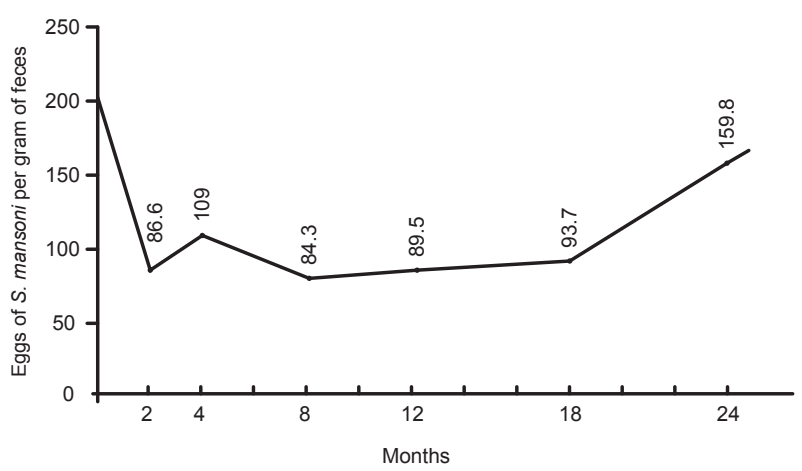

Fig. 3: drops of Schistosoma mansoni eggs (216-86.6 per gram of feces) in patients treated with oxammiquine and increasing in 24 months in São Geraldo do Baixio, Galiléia, Minas Gerais.

to control the infection. On the other hand, the hepatosplenic form, which was $5.8 \%$ in 1973 when the prevalence was $60.8 \%$, went down to $1.3 \%$ in 2003 .

We conclude that treatment alone reduces the prevalence of infection and the morbidity due to schistosomiasis, but does not control its transmission (Coura \& Camillo-Coura 1980, Coura 1995). Such transmission control is only possible through integrated measures over the short, medium and long terms; while this would seem to be an obvious protocol to implement, it has never been put into continuous practice in Brazil.

\section{REFERENCES}

Andrade ZA, dos Santos HA, Borojevic R, Grimaud JA 1974. Lesões hepáticas produzidas por hycanthone (Etrenol). Rev Inst Med Trop Sao Paulo 16: 160-170.

Bina JC, Prata A 1970. Hycanthone no tratamento da esquistossomose em uma área rural com baixo índice de transmissão da doença. $G a z$ Med Bahia 70: 127-138.

Bina JC, Prata A 1974. An attempt to control schistosomiasis mansoni in an endemic area by the use of hycanthone as chemotherapeutic agent. Rev Soc Bras Med Trop 8: 217-222.

Bina JC, Prata A 1980. Oxamniquine in the treatment of schistosomiasis in a population in area with low endemicity. Rev Inst Med Trop Sao Paulo 22 (Suppl. 4): 94-97.

Christopherson JB 1918. The successful use of antimony in bilharziosis: administered as intravenous injections of antimonium tartaratum (tartar emetic). The Lancet 192: 325-327.

Conceição MJ, Borges-Pereira J 2002. Influence of specific treatment on the morbidity of schistosomiasis mansoni in an endemic area of Minas Gerais, Brazil. Mem Inst Oswaldo Cruz 97: 755-757.

Conceição MJ, Borges-Pereira J, Coura JR 2007. A thirty years follow-up study on schistosomiasis mansoni in a community of Minas Gerais, Brazil. Mem Inst Oswaldo Cruz 102: 1007-1009.

Coura JR 1995. Control of schistosomiasis in Brazil: perspectives and proposals. Mem Inst Oswaldo Cruz 90: 257-260.

Coura JR, Amaral RS 2004. Epidemiological and control aspects of schistosomiasis in Brazilian endemic areas. Mem Inst Oswaldo Cruz 99 (Suppl. I): 13-19.

Coura JR, Argento CA, Conceição MJ, Lewis EM, dos Santos ML, Magalhães P 1980. Experiências de campo com oxamniquine oral no tratamento da esquistossomose mansoni. Rev Inst Med Trop Sao Paulo 22 (Suppl. 4): 195-202.

Coura JR, Argento CA, Cunha MC, Valente-Filho P, Rodrigues da Silva J 1963. Electrocardiographic changes during treatment of schistosomiasis with sodium antimony dimercapto-succinate $\left(\right.$ Astiban $^{\circledR}$ ) and Fouadin ${ }^{\circledR}$. Proceedings of the 7th International Congress on Tropical Medicine and Malaria, Gráfica Olímpica Editora, Rio de Janeiro, p. 127-128.

Coura JR, Argento CA, Figueiredo N, Wanke B, Queiroz GC 1973. Clinical trial with oxamniquine (UK4271) in the treatment of schistosomiasis mansoni. Rev Inst Med Trop Sao Paulo 15 (Suppl. 1): 41-46.

Coura JR, Camillo-Coura L 1980. Perspectivas de controle da esquistossomose com especial referência ao tratamento em massa. Rev Soc Bras Med Trop 13: 157-160.

Coura JR, Conceição J, dos Santos ML, de Mendonça ZG, Cutrim RN 1992. Cross-sectional and evolutive studies of schistosomiasis mansoni in untreated and mass treated endemic areas in the Southeast and Northeast of Brazil. Mem Inst Oswaldo Cruz 87 (Suppl. IV): 175-182.

Coura JR, Conceição MJ, Pereira JB 1984. Morbidade da esquistossomose mansoni no Brasil. III. Estudo evolutivo em uma área endêmica no período de dez anos. Mem Inst Oswaldo Cruz 79: 447-453.

Davis A, Wegner DH 1979. Multicentre trials of praziquantel in human schistosomiasis: design and techniques. Bull World Health Organ 57: 767-771.

Dias CB 1949. Quimioterapia antimonial na esquistossomose mansônica 1949: subsidio a seu estudo, PhD Thesis, Faculdade de Medicina da Universidade Federal de Minas Gerais, Belo Horizonte, 348 pp.

Foster R 1973. The preclinical development of oxamniquine. Rev Inst Med Trop Sao Paulo 15 (Suppl. 1): 1-9.

Foster R 1987. A review of clinical experience with oxamniquine. Trans $R$ Soc Trop Med Hyg 81: 55-59.

Ishizaki T, Kamo E, Boehme K 1979. Double-blind studies of tolerance to praziquantel in Japanese patients with Schistosoma japonicum infections. Bull World Health Organ 57: 787-791.

Jansen G 1946. Profilaxia experimental da esquistosomose de Manson. Mem Inst Oswaldo Cruz 44: 549-578.

Katz N 2008. Terapêutica clínica na esquistossomose mansoni. In OS Carvalho, PMZ Coelho, HL Lenzi (org.), Schistosoma mansoni $e$ esquistossomose: uma visão multidisciplinar, Editora Fiocruz, Rio de Janeiro, p. 850-870.

Katz N, Grinbaum E, Chaves A, Zicker F, Pellegrino J 1976. Clinical trials with oxamniquine, by oral route, in schistosomiasis mansoni. Rev Inst Med Trop Sao Paulo 18: 371-377.

Katz N, Pellegrino J, Grinbaum E, Chaves A, Zicker F 1973. Preliminary clinical trials with oxamniquine, a new antischistosomal agent. Rev Inst Med Trop Sao Paulo 15: 25-29.

Katz N, Rocha RS, Chaves A 1979. Preliminary trials with praziquantel in human infections due to Schistosoma mansoni. Bull World Health Organ 57: 781-785.

Katz N, Rocha RS, Pereira JP 1980. Schistosomiasis control in Peri-Peri (Minas Gerais, Brazil) by repeated clinical treatment and molluscicide application. Rev Inst Med Trop Sao Paulo 22 (Suppl. 4): 85-93.

Katz N, Zicker F, Pereira JP 1977. Field trials with oxamniquine in schistosomiasis mansoni-endemic area. Am J Trop Med Hyg 26: 234-237.

Katz N, Zicker F, Rocha RS, Oliveira VB 1978. Reinfection of patients in schistosomiasis mansoni endemic areas after specific treatment. Rev Inst Med Trop Sao Paulo 20: 273-278.

Kloetzel K 1963. Sobre a conveniência da quimioterapia da esquistossomose em população em contínuo contato com os focos. Rev Inst Med Trop Sao Paulo 5: 106-110. 
Kloetzel K 1972. Perspectivas para o controle da esquistossomose-doença. Rev Soc Bras Med Trop 6: 413-420.

Machado PA 1982. The Brazilian program for schistosomiasis control, 1975-1979. Am J Trop Med Hyg 31: 76-86.

Maciel H 1924. Algumas notas em torno do tratamento da schistosomose intestinal. Sci Med 3: 3-24.

Maciel H 1925. Contribuição para o estudo da schistosomose intestinal, Imprensa Naval, Rio de Janeiro, 147 pp.

Maciel H 1929. O tratamento da esquistossomose intestinal no Hospital da Marinha. Sci Med 7: 20-24.

Maciel J 1920. O tratamento da schistosomose americana. Bras Med 34: 127.

McDonagh JER 1915. Antimony in bilharziasis. Lancet 2: 371.
Prata A 1976. Experience in Brazil with the use of available schistosomicides in mass treatment campaigns. Rev Soc Bras Med Trop 10: 355-360.

Prata A, Bina JC, Barreto AC, Alecrim MG 1980. Attempt to control the schistosomiasis transmission by oxamniquine in an hyperendemic locality. Rev Inst Med Trop Sao Paulo 22 (Suppl. 4): 65-72.

Sette H 1953. O tratamento da esquistossomose mansoni à luz da patologia hepática, MSc Thesis, Faculdade de Medicina, Recife, 220 pp.

Silva JR 1955. Quimioterapia por via oral na esquistossomose mansoni, Thesis, Faculdade de Ciências Médicas, Rio de Janeiro, 220 pp.

Silva JR 1958. Avaliação dos resultados da terapêutica específica da esquistossomose mansoni em uma campanha de saúde pública no Brasil. Proceedings of the 6th International Congress on Tropical Medicine, Lisboa, p. 89-100. 